\title{
Audit of Surgery For Acute Appendicitis in National Medical College and Teaching Hospital, Birgunj
}

\author{
Yadav $\mathrm{UK}^{1}$, Bhatt $\mathrm{PN}^{2}$, Mishra $\mathrm{GN}^{3}$, Maharjan $\mathrm{S}^{4}$, Gurung $\mathrm{P}^{5}$
}

\begin{abstract}
Background: Acute appendicitis is one of the most common surgical emergencies in the world. The purpose of this study is to know clinical profile and outcome of surgery in patients with acute appendicitis. Materials and methods: This retrospective study was done in National Medical college and Teaching Hospital, Birgunj, Nepal from 2013 April to 2016 April. A total of 184 patients with suspected appendicitis who underwent surgery were included in the study. Patient's demographics, clinical features, white blood cell count, operative findings, histology report and outcome of surgery were recorded on patient's proforma. Results: Among 184 patients, 115 were males (62.5\%) and 69 were females (37.5\%). The majority of our patients were in the $2^{\text {nd }}$ decade (36.4\%) followed by $3^{\text {rd }}$ decade $(33.2 \%)$ with only $41.3 \%$ presenting within 24 hours of onset of symptoms. The most common symptoms were abdominal pain (100\%), vomiting (68.5\%), fever (37.5\%) and history of migration of pain was present in $60.9 \%$. Localized and generalized abdominal tenderness were present in $91.8 \%$ and $8.2 \%$ respectively. The most common incisions were gridiron (64.1\%) and Lanz (27.2\%). The negative appendicectomy rate was 9.2\%. Acute appendiceal inflammation and gangrenous appendicitis was present in $69 \%$ and $4.9 \%$ respectively. The perforation rate was $16.8 \%$. Post operative complications included surgical site infection $(12.6 \%)$, complete wound dehiscence (1.1\%) and chest infection (1.6\%). The median length of hospital stay was 8 days. There was no mortality. Conclusion: Acute appendicitis is more commonly seen in young adults. Majority of patients present late in hospital. This delay presentation increases morbidity and treatment cost.
\end{abstract}

\section{Key words: Appendicitis, appendectomy, audit, NMCTH}

\section{INTRODUCTION}

Acute appendicitis is one of the most common surgical emergencies and is the commonest cause of abdominal pain requiring hospital admission. ${ }^{1}$ Appendicitis can occur in any age group but is common in childhood and early adult life. Early diagnosis and prompt operative treatment is required to prevent serious complications. This retrospective study was carried out with the objective to know the clinical presentation, pathological features and outcome of surgery.

\section{MATERIALS AND METHODS}

This study was conducted in National Medical College and Teaching Hospital, Birgunj during 3 years period from 2013 April to 2016 April and case records of patients who underwent surgery for suspected appendicitis were analyzed retrospectively. Patient demographics, clinical features, white blood cell count, type of incision, operative findings,
1. Dr. U. K. Yadav
2. Dr. Pashupati Nath Bhatt
3. Dr. Gorakha NathMishra
4. Dr. SunderMaharjan
5. Dr. Pramod Gurung

Address for correspondence:

Dr. Umesh Kumar Yadav

Department of Surgery

National Medical College \& Teaching Hospital

Birgunj, Nepal

Email: kumardrumesh07@gmail.com histological findings, postoperative complications were recorded on proforma. Appendicectomy was indicated when there was high suspicion of acute appendicitis based on symptoms and signs. White blood cell count (WBC) was used as complimentary findings, ultrasound scan was performed when clinical features were equivocal.

All specimens were examined routinely for morphology and sent for histopathological examination for final diagnosis. Negative appendicectomy is one which is performed for diagnosis of acute appendicitis but on histopathological examination, appendix is found to be normal. Patients treated conservatively or surgically after failed initial conservative treatment were excluded from the study and those who had elective appendicectomy (whether or not part of another operation) also excluded. The white blood cell count was considered positive when it was equal or greater than $10 \times 10^{9}$ per litre.

\section{RESULTS}

Demographics

A total 184 patients underwent emergency appendicectomy during the study period. Out of 184 cases, there were 115 (62.5\%) males and 69(37.5\%) females. The most commonly affected age group was $11-20$ years (36.4\%) followed by $21-30$ years(33.2\%; Figure 1$)$. The youngest patient was 4 years old and the oldest patient was 79 years old. The median age of patient was 23 years. 


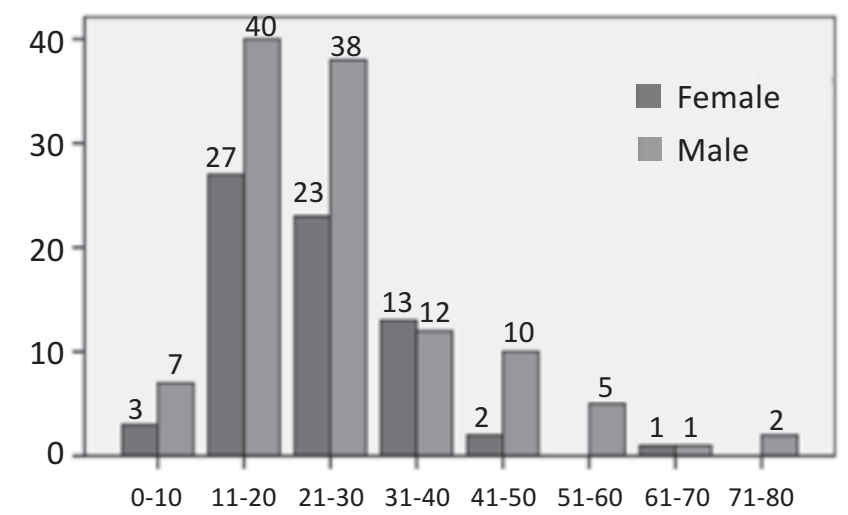

Figure 1: Age and gender distribution of patients with acute appendicitis

\section{Clinical features}

\section{Symptoms}

The most common complaints were abdominal pain (100\%), vomiting (68.5\%), and fever (37.5\%; Table 1). Anorexia was present in $13.1 \%$ and $4.3 \%$ patients had loose motions. History of migration of pain was present in $60.9 \%$ and $41.3 \%$ patients presented within 24 hours of onset of symptoms.

\section{Signs}

Localised and generalised abdomen tenderness was present in $91.8 \%$ and $8.2 \%$ patients respectively. Rebound tenderness was present in $72.8 \%$. Raised WBC ( $\geq 10 \times 10^{9}$ per litre) level was noted in $65.2 \%$ of patients.

\begin{tabular}{|l|c|}
\hline Median age (years) & 23 \\
\hline Sex ratio (M:F) & $115: 69$ \\
\hline Symptoms & $184(100)$ \\
\hline Abdominal pain & $112(60.9)$ \\
\hline Migratory pain & $126(68.5)$ \\
\hline Vomiting & $69(37.5)$ \\
\hline Fever & $26(14.1)$ \\
\hline Nausea & $24(13.1)$ \\
\hline Anorexia & $8(4.3)$ \\
\hline Loose stool & $5(2.7$ \\
\hline Dysuria & $169(91.8)$ \\
\hline Signs & $15(8.2)$ \\
\hline Localized tenderness & $134(72.8)$ \\
\hline Generalized tenderness & $76(41.3)$ \\
\hline Rebound tenderness & \\
\hline Presentation within 24 hrs & \\
\hline of symptoms & \\
\hline Values in bracket are percentages & \\
\hline
\end{tabular}

Table I: Demographic and clinical feature of patients with acute appendicitis

\section{Operative findings}

At surgery, uncomplicated appendicitis was found in $70.1 \%$ of patients and $20.7 \%$ of the patients were found to have complicated appendicitis (Table 2) and the normal appendices were present in $8.2 \%$. Of grossly normal appendices, another underlying pathology was found in $4(2.2 \%)$ patients and out of 4 patients, 3 were females ( 2 had bleeding from ovary and 1 had inflamed ovary) and 1 male patient with inflamed terminal ileum. Perforation was present in $15.8 \%$ of patients - male $8.7 \%$ and female $7.1 \%$. The most common incisions were gridiron incision (64.1\%) and Lanz incision (27.2\%). Other incisions were Rt. Paramedian (4.9\%) and lower midline (3.3\%). Laparoscopic appendicectomy was done in 1 patient. Primary skin closure was done in 167 (90.8\%) and delayed primary skin closure was done in $17(9.2 \%)$ patients.

\begin{tabular}{|l|c|}
\hline Total & $\mathrm{n}=184$ \\
\hline Appendicectomy & $183(99.45)$ \\
\hline Open & $1(0.54)$ \\
\hline Laparoscopy & \\
\hline Open surgery & $118(64.1)$ \\
\hline Grid-iron incision & $50(27.2)$ \\
\hline Lanz incision & $9(4.9)$ \\
\hline Rt paramedian incision & $6(3.3)$ \\
\hline Lower midline incision & $129(70.1)$ \\
\hline Intraoperative findings & $38(20.7)$ \\
\hline Uncomplicated appendicitis & $15(8.2)$ \\
\hline Complicated (gangrenous or & $11(6.0)$ \\
\hline perforation) appendicitis & $4(2.2)$ \\
\hline Grossly normal appendix & $2(1.1)$ \\
\hline Without other pathology & $17(9.9)$ \\
\hline With other pathology & $167(90.8)$ \\
\hline Faecolith & $17(9.2)$ \\
\hline Skin closure & \\
\hline Primary & $127(69.0)$ \\
\hline Delayed primary & \\
\hline Histological findings & \\
\hline Acute appendicitis & \\
\hline Perforation & \\
\hline Gangrenous & \\
\hline Normal appendix & \\
\hline Rt- Right; values in brackets are percentages \\
\hline
\end{tabular}

\section{Table II: Operative data for patients undergoing} appendicectomy for acute appendicitis

\section{Histological findings}

Acute appendicitis was seen in $69 \%$ of patients and the negative appendicectomy rate was $9.2 \%-6.5 \%$ in females and $2.7 \%$ in males. The perforation rate was $16.8 \%-8.7 \%$ in males and $7.1 \%$ in females. $14.7 \%$ perforation was found in patient who presented after $24 \mathrm{hrs}$. of symptoms. 


\section{Morbidity and mortality}

Most common complication was surgical site infection (SSI). Out of 167 patients, $21(12.6 \%)$ patients developed surgical site infection. Out of 21 , superficial SSI was seen in $17(10.2 \%)$ and $4(2.4 \%)$ patients developed deep SSI. Of the $15(8.2 \%)$ patients who were complicated by diffuse peritonitis, 2(1.1\%) developed complete wound dehiscence and $3(1.6 \%)$ patients developed chest infection. There was no mortality.

\section{DISCUSSION}

In this study, acute appendicitis occurred most commonly during $2^{\text {nd }}$ decade of life accounting for $36.4 \%$ followed by $3^{\text {rd }}$ decade of life (33.2\%) which is comparable with reports ${ }^{2,3}$. There was male predominance (M:F,1.7:1) comparable to other reports ${ }^{2,4,5}$. Study done by C. C. van Rossem et al ${ }^{6}$ revealed slightly female predominance (M:F, 0.9:1). Only $41.3 \%$ patients presented within 24 hours of onset of symptoms and this trend is common in other reports ${ }^{2,7}$. The most common symptoms in our patients were abdominal pain (100\%), vomiting (68.5\%) and fever (37.5\%) similar to series. ${ }^{2}$ The classical presentation (migratory pain) was present in $60.9 \%$ of patients but in study by Madiba TE et al ${ }^{8}$ revealed that only $16 \%$ of patients had classical presentation. The most common surgical incision was gridiron (64.1\%) which is comparable to report ${ }^{6}$. In that study, 96.5\% patients had gridiron incision. The type of incision is mainly depends upon the surgeon's choice. In our study, laparotomy was done in $8.2 \%$ of the patients, comparable to report from UK ${ }^{9}$ but in the study done by I Chamisa ${ }^{2}$ revealed that $47.2 \%$ patients had lower midline incision which probably reflects high rate of delayed presentation with complicated appendicitis.

In this series, the negative appendicectomy rate was $9.2 \%$ comparable to series ${ }^{8}$. Negative appendicectomy rate was found higher in females as compared to series. The study ${ }^{6}$ revealed low rate of normal appendicectomy and in that study, they had used imaging modality almost in every patient to diagnose acute appendicitis and histologically normal appendix was found in $2.2 \%$. Studies ${ }^{10,11}$ have shown the effectiveness of imaging techniques in reducing normal appendicectomy rate. Reports ${ }^{2,5}$ have shown the higher rate of negative appendectomy. In our study, only one patient had laparoscopic appendectomy. The perforation rate on histology was $16.8 \%$ and this is comparable to report ${ }^{12}$ but higher than the report published in the literature ${ }^{6}$ and in that study, perforation was found in $11.0 \%$. Reports ${ }^{2,13}$ have shown higher rate of perforation. Colson et al ${ }^{14}$ proposed that a delay in presentation of $>12$ hours after onset of symptoms increase perforation rate. In our study, there was direct correlation between perforation and delayed presentation.

Postoperative complications were evaluated in the $1^{\text {st }}$ month of the operation and we had no data on long term follow up. SSI was the most common complication seen in $12.6 \%$ of patients comparable to the report ${ }^{15}$ and lower than the report ${ }^{2}$. The median length of the hospital stay was 8 days and this is higher than the report ${ }^{6}$. For the 17 patients who developed Superficial SSI, median length of hospital stay was 10 days and for the 4 patients who developed deep SSI, the median length of hospital stay was 12.5 days.

\section{CONCLUSION}

Acute appendicitis can occur in any age group but more commonly seen in young adult. Majority of our patients present late in the hospital which may increase the number of complicated appendicitis, morbidity and treatment cost.

\section{REFERENCES}

1. Ali A.Al Katib, Ali H.AL Timimi. Acute appendicitis clinicpathological study. Medical Journal of Babylon 2004; 1(2):162167.

2. I Chamisa. A clinicopathological review of 324 appendices removed for acute appendicitis in Durban, South Africa: a retrospective analysis. Ann R Coll Engl 2009; 91: 688-692.

3. Vilela Desposorio CD, Cusma Quintana TN. Association between appendiceal obstruction and the morphological type of acute appendicitis. Rev Gastroenterol Peru 2015;35(1): 32-7.

4. Fulton J, Lazarus C. Acute appendicitis among black South Africans. S Afr J Surg 1995; 33:165-6.

5. Levy RD, Degiannis E, Kantarovsky A, Maberti PM, Wells M, Hatzitheofilou C. Audit of acute appendicitis in a black South African population. S Afr J Surg 1997;35(4):198-202.

6. C.C. van Rossem, MDM Bolmers, MHF Schreinemacher, AAW van Geloven, WA Bemelman. Prospective nationwide outcome audit of surgery for suspected acute appendicitis. BJS 2016; 103:144151.

7. Willmore WS, Hill AG. Acute appendicitis in Kenyan Rural Hospital. East Afr Med J 2001; 78:355-7.

8. Madiba TE, Haffejee AA, Mbete DL, Chaithram H, John J. appendicitis among African patients at King Edward VIII Hospital, Durban, South Africa: a review. East Afr Med J 1998 Feb; 75(2):814.

9. Lansdown MRJ, Gray AJG, Treasure T, Layer GT. Appendicectomy: who performs it, when and how? Ann R Coll surg Engl 2006; 88: 530-4.

10. Park JS, Jeong JH, Lee JI, Lee JH, Park JK, Moon HJ. Accuracies of diagnostic methods for acute appendicitis. Am Surg 2013; 79: 101-106.

11. Raja As, Wright C, Sodickson AD, Zane RD, Schiff GD, Hanson R et al. Negative appendicectomy rate in the era of CT: an 18 year perspective. Radiology 2010; 256:460-465.

12. Korner H, Sondenaa K, Soreide JA, Andersen E, Nysted A, Lende $\mathrm{TH}$ et al. Incidence of acute nonperforated and perforated appendicitis: age-specific and sex-specific analysis. World J Surg 1997 Mar-Apr;21(3):313-7.

13. Rogers AD, Hampton MI, Bunting M, Atherstone AK. Audit of appendicectomies at Frere Hospital, Eastern cape. S Afr J Surg 2008 Aug; 46(3):74-7.

14. Colson $M$, skinner Ka, Punnington $G$. High negative appendicectomy rates are no longer acceptable. Am J Surg 1997;174:723-6.

15. Golub AV, Kozlov RS, Pleshkov VG, Moskalev AP, Alibegov RA, Chelombitko MA. Surgical site infections after open appendectomy and effectiveness of complex approach to their prevention. Khirurgiia (mosk) 2016;(6):68-76. 